\title{
Memento Park. Naturaleza histórica del siglo XX
}

\author{
Rodrigo RIEIRO DÍAZ \\ Departamento de Proyectos Arquitectónicos \\ ETSAM / Universidad Politécnica de Madrid \\ rodrigo_rieiro@hotmail.com
}

Recibido: 22/08/2012

Modificado: $01 / 03 / 2013$

Aceptado: $17 / 03 / 2013$

\section{Resumen}

Este trabajo parte de un recorrido por Memento Park, parque donde se hallan almacenadas las estatuas de los antiguos dirigentes comunistas en Budapest, para ordenar una colección distraída de imágenes sobre otras ruinas del pasado reciente. El objetivo es articular paradojas concretas de montajes visuales con paradojas teóricas de montajes temporales, con la intención de responder a las preguntas: ¿las imágenes del pasado reciente nos puedan informar sobre las disposiciones materiales del presente?, ¿es posible que éstas nos activen?

Palabras clave: alegoría, ruina, Walter Benjamin, Budapest.

Title: Memento Park. Historical Nature of the XXth Century

\section{Abstract}

This paper starts from a tour through Memento Park, a place in Budapest where the statues of the former communist leaders are stored today, to arrange a collection of pictures about other ruins of the recent past. The aim is to articulate specific paradoxes of visual montages with theoretical paradoxes of temporal montages, pretending to answer the questions: can the images from the recent past inform us about the material arrangements of the present?, could they activate us?

Keywords: allegory, ruin, Walter Benjamin, Budapest. 
Memento Park Budapest. Los gigantescos recuerdos de la dictadura comunista. Así se encabeza la página web de este parque temático del honfibú ${ }^{1}$, junto a una fotografía al azar -una cada recarga de la página- de alguna de las cuarenta y dos estatuas de la época comunista que en un pasado reciente formaron parte de la mitología de los húngaros. Éstas, ahora todas juntas en una finca en el borde de la ciudad, forman una suerte de Parco dei Mostri contemporáneo, dedicado al turismo y a la memoria.

Entre los postes eléctricos, la maleza de los descampados y algunas pequeñas construcciones auxiliares, se hallan diseminadas las estatuas de los personajes míticos del pasado reciente, como dioses caídos ${ }^{2}$. Precisamente ese mismo precio, el de la pérdida de la divinidad y su transformación en lo demoníaco, fue el que las deidades paganas tuvieron que pagar para sobrevivir a la era cristiana. En su texto sobre el drama barroco, Walter Benjamin señala que la interpretación alegórica de estas deidades se transformó en su "única salvación concebible". Sin ella, "en un contexto inadecuado, en realidad hostil, [...] el mundo de los antiguos dioses hubiera tenido que morir, y es precisamente la alegoría quien lo rescató" (Benjamin 1990: 398).

Benjamin defendió que la alegoría barroca era algo más que una mera sobrecodificación que realzase mediante la profundidad -y autoridad- del misterio algún precepto moral, era más bien "el modo en el que el mundo objetivo, no el objeto, expresa significado" (BuckMorss 1995: 253). Ninguna lejanía, sino "el trabajo desde la misma superficie de los fragmentos" (García García 2010: 171).

Su proyecto fue el de la construcción de una explicación política del "mundo cultural circundante en las sociedades capitalistas desarrolladas, en las que el colectivo social convive en su vida cotidiana con edificaciones y productos industriales del pasado reciente" (Romero Cuevas 2010: 368).

\footnotetext{
${ }^{1}$ El honfibú o tristeza patriótica define un estado de ánimo general marcado por la melancolía que supuestamente definiría a los húngaros, de un modo similar a lo que sucede con la saudade de los portugueses o la morriña de los emigrantes gallegos.

2 "Ya en su visita a Moscú en 1926, Walter Benjamin llamaba la atención sobre los 'iconos de Lenin como réplicas de la Revolución para turistas y ésta, como antes la religión, corre el riesgo de ser reificada y dominar al pueblo que la creó'" (BuckMorss 1995: 46).
} 
RIEIRO DÍAZ, Rodrigo (2013): "Memento Park. Naturaleza histórica del siglo XX" [en línea]. En: Ángulo Recto. Revista de estudios sobre la ciudad como espacio plural, vol. 5, núm. 1, pp. 65-85. En: http://www.ucm.es/info/angulo/volumen/Volumen05-1/articulos04.htm. ISSN: 1989-4015

http://dx.doi.org/10.5209/rev_ANRE.2013.v5.n1.42068
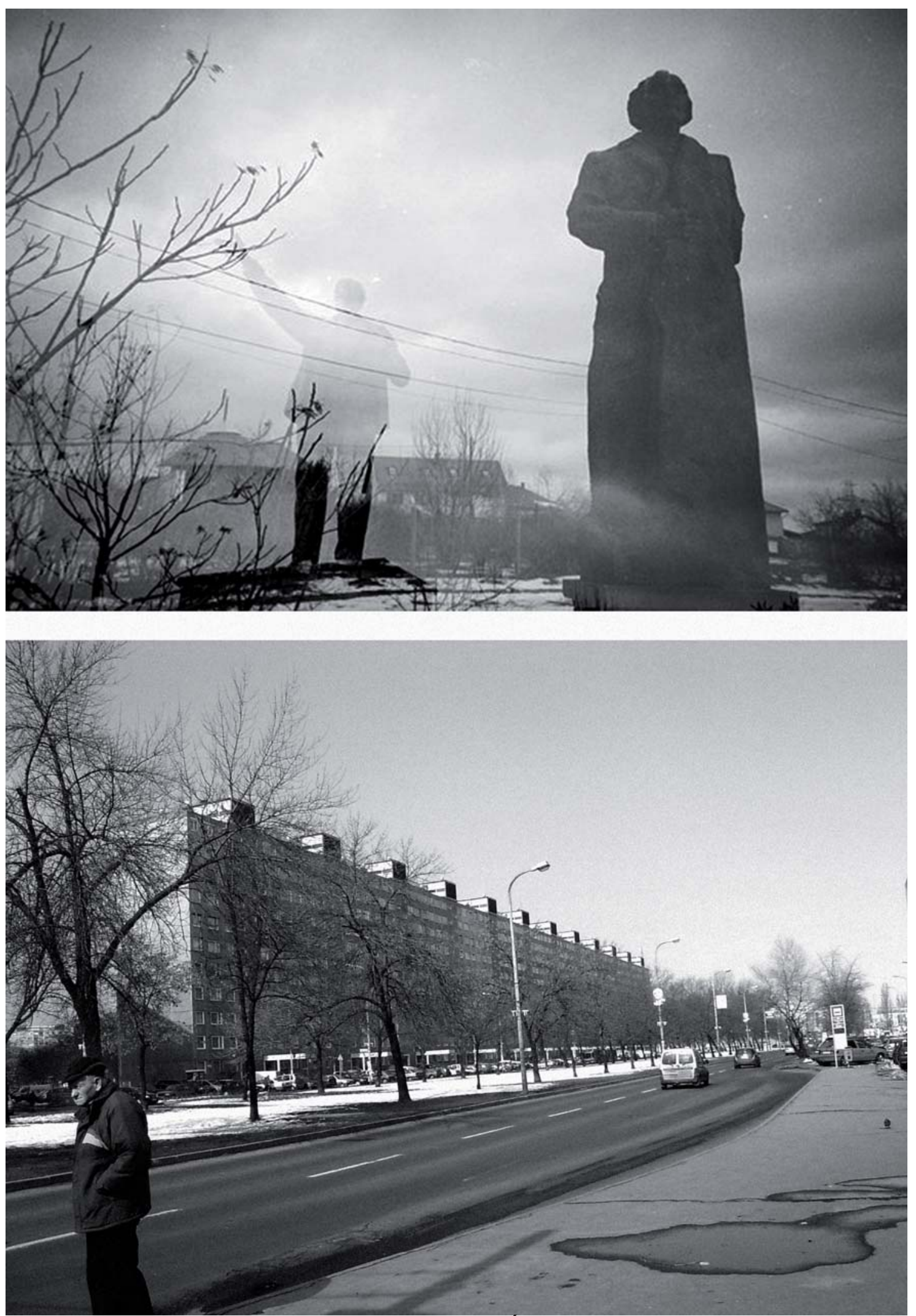

Figura 1. Memento Park y Újapalotai (2006). 
Para ello, Benjamin se sirve de la alegoría. El material desechado de épocas anteriores podría ser elevado, a través de ésta, a fuente de conocimiento sobre la verdad histórica.

La primera pregunta que nos planteamos en este texto es si la semántica del fragmento benjaminiana es aplicable a los desechos de nuestra propia época. Si éstos nos pueden hablar y qué nos dirían de nuestro pasado reciente, a través de un recorrido por el parque de estatuas húngaro.

El Memento Park de Budapest encierra el rechazo de un pasado rechazado, compuesto de objetos históricos desgajados de la historia secuencial, estallados fuera del continuo histórico y descontextualizados del espacio para el que fueron concebidos; y no tenemos que ir muy lejos para comprobar que el peculiar modo en que el pasado se entrelaza con la trama del presente en el Memento Park se manifiesta en otras ruinas cercanas en el espacio y el tiempo.

Újpalota -el palacio nuevo- es el principal desarrollo urbano de la Hungría de Kádar János (figura 1). Por la rapidez de su ejecución del 68 al 77- y su gran extensión -15.886 viviendas- es el ejemplo más significativo de la versión húngara del plattenbau: el panelház. Este sistema de habitación proliferó extraordinariamente en el área de influencia soviética durante el mandato de Jrushchov en la URSS. En concreto, en Budapest, casi una de cada cuatro personas viven en una de estas unidades de vivienda (Otthon Centrum 2006).

Sin embargo, un paseo a mediodía por Újpalota deja en evidencia su condición ruinosa. De los más de 60.000 habitantes que llegó a tener en la década de los 80, en la actualidad sólo 33.000 personas viven aquí ( $\mathrm{MH}$ 2012). Tras la caída del régimen en el año 1989 y la consiguiente privatización de la vivienda, se han dado ciertos movimientos migratorios internos en la ciudad. El abandono de este extenso polígono de vivienda, relativamente nuevo y no muy alejado del centro, no es ajeno a su condición simbólica. El Studio Metropolitana sobre popularidad urbana del Urbanisztikai Kutatóközpont (el Centro de Investigación de Planificación Urbana de la ciudad) situaba a Újapalotai en el puesto 12 de los 14 barrios de la ciudad (UK 2010).

Sin embargo, para acudir al verdadero teatro de la Hungría del socialismo real hay que ir un poco más lejos -y un poco más atrás en el tiempo-. Dunaújváros -la cuidad nueva del Danubio, antes Sztalinváros- fue la primera, y la más importante, de las catorce nuevas ciudades que se levantaron en la Hungría de postguerra, de las que se dijo que "su madre fue la minería y su padre la economía planificada" (Germuska 2008). Se erigió principalmente entre el 49 y el 61 en el curso del Danubio, unos $50 \mathrm{~km}$ al sur de Budapest y junto al polo de industria pesada estatal Dunaferr, aún hoy uno de los principales del país. 
La idea de la ciudad ideal de los trabajadores a imagen de una nueva sociedad encaja en la línea de planeamiento de la época estalinista, en la que había una creencia resuelta en la omnipotencia de la planificación.

Weiner Tibor, el arquitecto de este Magnitogorsk gulyás, se formó junto a Hannes Meyer en el Moscú de los años 30, para después colaborar varios años con Grete Schütte-Lihotszky en París. Pese a esta formación impecablemente moderna, la función representativa resultó fundamental en el diseño de la ciudad, que fue ordenada en torno a Vasnû Út -la avenida de la Siderurgia-, "creando una relación estrecha a nivel espacial y de espectáculo con el polo industrial" (Germuska 2008).

Los cambios políticos del 53, con la muerte de Stalin y los alzamientos obreros en Berlín Este, seguidos de la revolución húngara del 56, tuvieron una gran influencia en las nuevas ciudades socialistas húngaras. En general, supusieron una evolución desde el urbanismo más representativo de la época estalinista hacia el panelház.

Para Dunaújváros implicó, además del cambio de nombre, dos consecuencias. Por un lado, ni la plaza ni el centro monumental planificados fueron finalmente creados. Por el otro, restaurada la dominación rusa tras la imposición del gobierno de Kádár, la ciudad pasó a simbolizar la nueva sociedad socialista húngara y, con ello, su inclusión en la mitología particular de al menos un par de generaciones magiares. Dunaújváros fue una presencia constante en la cultura de masas del socialismo gulyás, como Nueva York o París lo pueden ser de la nuestra.

Se lanzaron ediciones de sellos y colecciones de postales, y sirvió como escenario de novelas o espectáculos musicales, pero, sobre todo, se convirtió en el set de rodaje de numerosas películas de la productora estatal Hunnia.

Kölyök (Chiquilla), de Szemes Mihály (1959), es el ejemplo más conocido de estas películas costumbristas y ligeramente moralizantes. La historia de la huérfana -protagonizada por la entonces muy popular Törôcsik Mari- acompaña largos planos secuencia descriptivos de la ciudad. El largometraje se convierte así en un publirreportaje de Dunaújváros $y$, con ello, del modelo sociocultural que supuestamente encarna y del que pasa a convertirse en símbolo en la fantasmagoría popular (figura 2).

La condición simbólica, la correspondencia biunívoca, construida por la industria cultural del socialismo real para la ciudad de Dunaújváros es equivalente a la de las estatuas que hoy se hallan en el Memento Park. También lo es la condición ruinosa de ambas, tras el ocaso de la civilización que las engendró. La ciudad, que llegó a tener más de 62.000 habitantes a finales de los años 80 , ha perdido cerca de una cuarta parte de su población (Hozzáférés 2011) fruto de 
una evolución que, no siendo ajena a los procesos de reconversión de la industria pesada en toda Europa, tampoco lo es a su condición simbólica.

Dunaújváros -Kölyök en particular- desvela al régimen de Kádár como un régimen de publicidad. Su fórmula de unidad nacional, patriotismo y fomento del consumo, que apela al colectivo en un estado de ensueño, es familiar también en nuestro contexto histórico.

En la construcción mítica de la fantasmagoría del socialismo real húngaro, fue central la revolución comunista que tuvo lugar en Budapest y la fugaz República Soviética de Hungría que, entre marzo y agosto de 1919, dirigió el país tras el desmoronamiento del Imperio Austrohúngaro en la Primera Guerra Mundial.
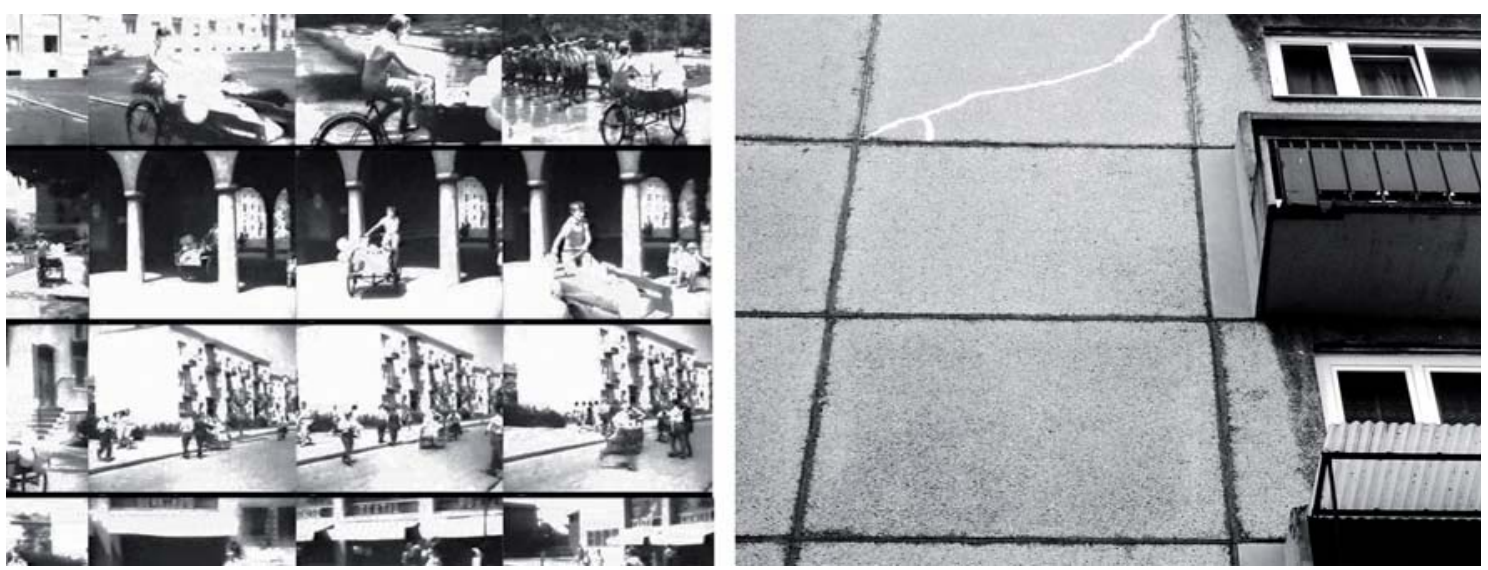

Figura 2. Dunaújavros, escenario de Kölyök en 1959; Dunaújváros (2006).

El escenario central de esta revolución popular fue el barrio obrero de Csepel. El principal polo industrial de Budapest, situado en una isla del Danubio junto al puerto fluvial, ha sido, desde la industrialización a finales del XIX, foco recurrente de insurrección política y cuenta con una peculiar tradición de guerrilla urbana.

Los últimos consejos obreros resistentes ante la invasión blanca rumana en el 19 se hallaban en Csepel, y su destacado papel en el proceso revolucionario dio al barrio un lugar en la historiografía mítica de la posterior República Popular. Un busto a Kalamár Jozsef, heroico dirigente revolucionario del barrio, descansa en el Memento Park. Sin embargo, "las distintas fases de la lucha social, o mejor, de la sociedad como lucha" (Delgado 2007: 107) se ajustan mal a la mitificación. La verdad histórica es que Kalamár fue torturado y asesinado por nuevas guerrillas urbanas en el Csepel de la revolución anticomunista del 56 (Hegedûs 2008). También entonces, los últimos focos de insurrección fueron sofocados en este polígono industrial.

Difícilmente los pocos emigrantes transilvanos que hoy viven y trabajan entre las últimas fábricas en funcionamiento del extenso polígono industrial de Csepel Mûvek podrían hoy organizar ningún 
alboroto. Entre ellos, como en el parque Memento, tan solo los phantasma ${ }^{3}$.

Este almacén de las ruinas de lo que fue conocido como socialismo real se constituye en sí mismo en una ruina, como emblema de la fragilidad de la cultura que lo engendró. "La destrucción de los monumentos que fueron construidos para significar la inmortalidad de la civilización se transforman en cambio en pruebas de su transitoriedad" (Buck-Morss 1995: 193).

No es el socialismo real la única ideología cuyas ruinas se encierran hoy entre los muros del Memento Park. Incluye en él los escombros de al menos otras tres ideologías que han condicionado la historia de Europa durante el siglo XX: el imperialismo colonialista (del Imperio Austrohúngaro) y el capitalismo feroz que sucedió a la debacle del régimen económico imperante en los países del este, entrelazados ambos con el nacionalismo húngaro que les ha servido de coartada.
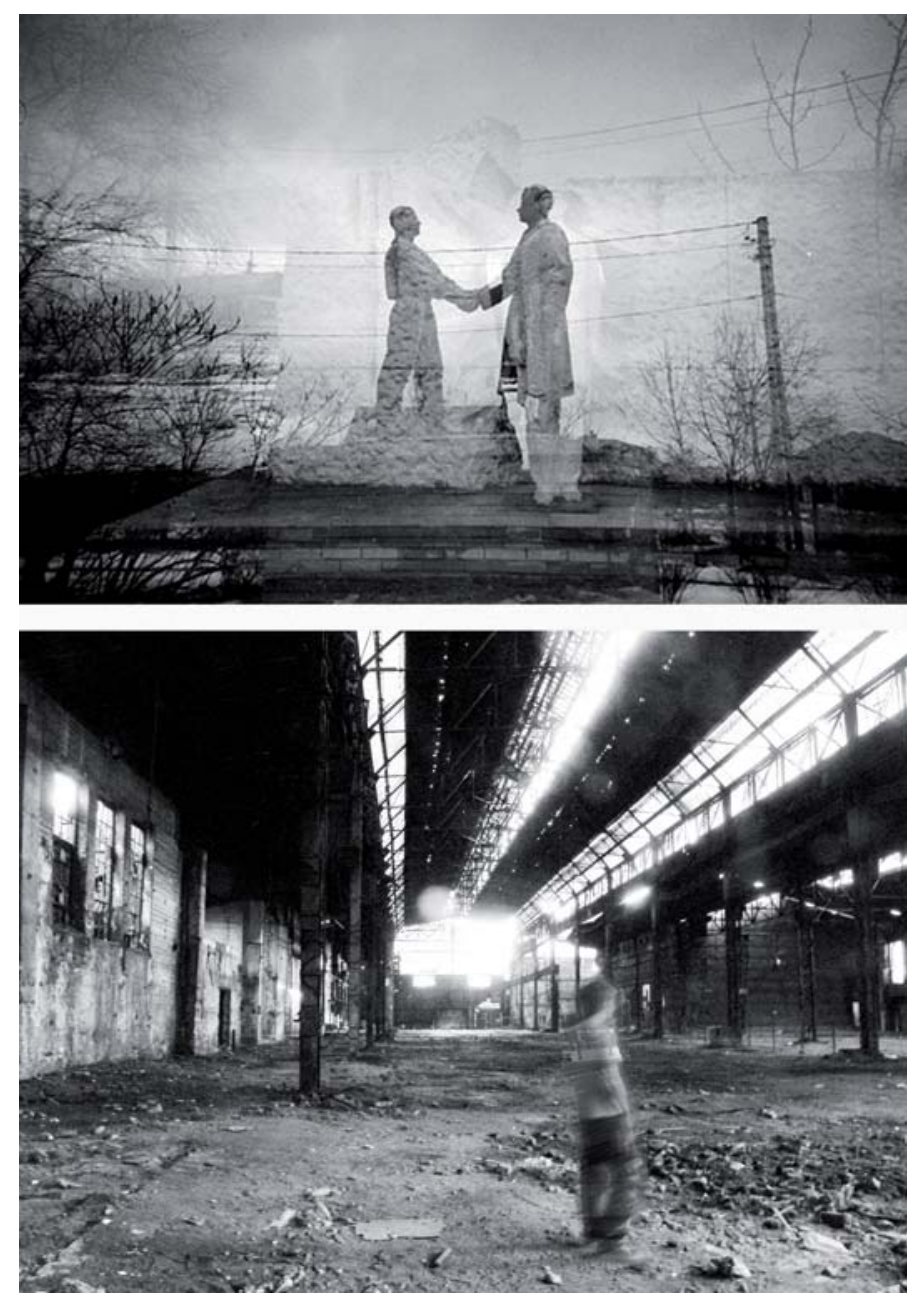

Figura 3. Memento Park; Csepel (2006).

3 En el sentido de imágenes inmateriales relacionadas con la memoria, la imaginación y el tiempo. 
El interés del Memento Park reside en que es una condensación de las ruinas del mundo exterior, lo que es particularmente notorio en su entorno espacio-temporal más próximo: la ruinosa ciudad de Budapest actual. Su importancia radica en que el parque de las estatuas se puede constituir en emblema de la ciudad entera porque Budapest en sí condensa las ruinas ideológicas que, desde el pasado reciente, nos informan de la materia con la que está hecho nuestro presente. Budapest es la primera derivada, el Memento Park la segunda.

La particular disposición de acontecimientos históricos del siglo $X X$ en Budapest hace posible que se dé esta densificación en la ciudad. Éstos no son muy diferentes a los de muchas otras ciudades europeas -de Alemania del Este en particular-; la singularidad de Budapest reside en que la destructividad de los periodos de crisis, lo prolongado de sus efectos económicos y su concatenación en el tiempo han dado poca oportunidad al maquillaje.

Uno de los principales objetivos del proyecto de Benjamin al "adoptar el punto de vista de lo que ha sido excluido" (Romero Cuevas 2004: 169) para mirar hacia la destrucción de la naturaleza material, tal como ésta realmente ocurrió, es proporcionar "un contraste dialéctico al mito futurista del progreso histórico -que sólo puede afirmarse a través del olvido de lo ocurrido-" (Buck-Morss 1995: 112). El olvido de lo ocurrido se hace particularmente difícil cuando las huellas materiales del pasado reciente se acumulan del modo en que lo hacen en Budapest. Las imágenes son los "pequeños, particulares momentos concretos en los que el acontecimiento histórico total" puede ser descubierto, el "perceptible ur-fenómeno en el que podían hallarse los orígenes del presente" (Benjamin 2005: 574).

La disposición en planta del Parque Memento evidencia la ruina de la ideología imperial austrohúngara en Budapest. Todo Pest, la ciudad en la margen izquierda del Danubio, se compone a base de anillos y radios, partiendo de la confluencia del cruce entre Cardo y Decumano, de la antigua Aquincum romana. La misma composición académica a base de simetrías y ejes que encontramos en el trazado haussmaniano de este París que no perdonó Hitler, se reproduce en el depósito de estatuas del extrarradio. Incluso el acceso al parque temático, completamente kitsch, aparece como un trasunto posmoderno del neoclásico Museo Nacional. Este estilo fue un sistema de legitimación mitológica empleado por la burguesía decimonónica europea, con la antigüedad clásica como referente. "El neoclasicismo no era la recurrencia de una forma eternamente válida, sino un peculiar estilo burgués de distorsión histórica. Representó a la burguesía representando a la antigüedad" (Buck-Morss 1995: 168). Ésta era así erigida en mito histórico legitimador de la ideología imperialista que culminó en la Primera Guerra Mundial. 
Esta ideología, también en su variante húngara, se combina con la reivindicación nacionalista de ciertos mitos fundacionales 0 coloniales, a través de otros neos -neomudéjar madrileño, neogótico,...-. En este caso es el de siete tribus magiares que, unificadas por el legendario Árpád, salieron de las estepas cercanas a los montes Urales para encontrar en las Ilanuras del Danubio su tierra prometida. La composición en planta de Ákos Elelöd, con siete círculos unidos, como un sólo poblado de siete yurtas, difícilmente puede haber sido ajeno a esta simbología (figura 4). De hecho, el Memento Park tiene un importante componente simbólico para el renovado nacionalismo húngaro, dado el componente de ocupación extranjera que tuvo el comunismo en Hungría después de la Segunda Guerra Mundial.
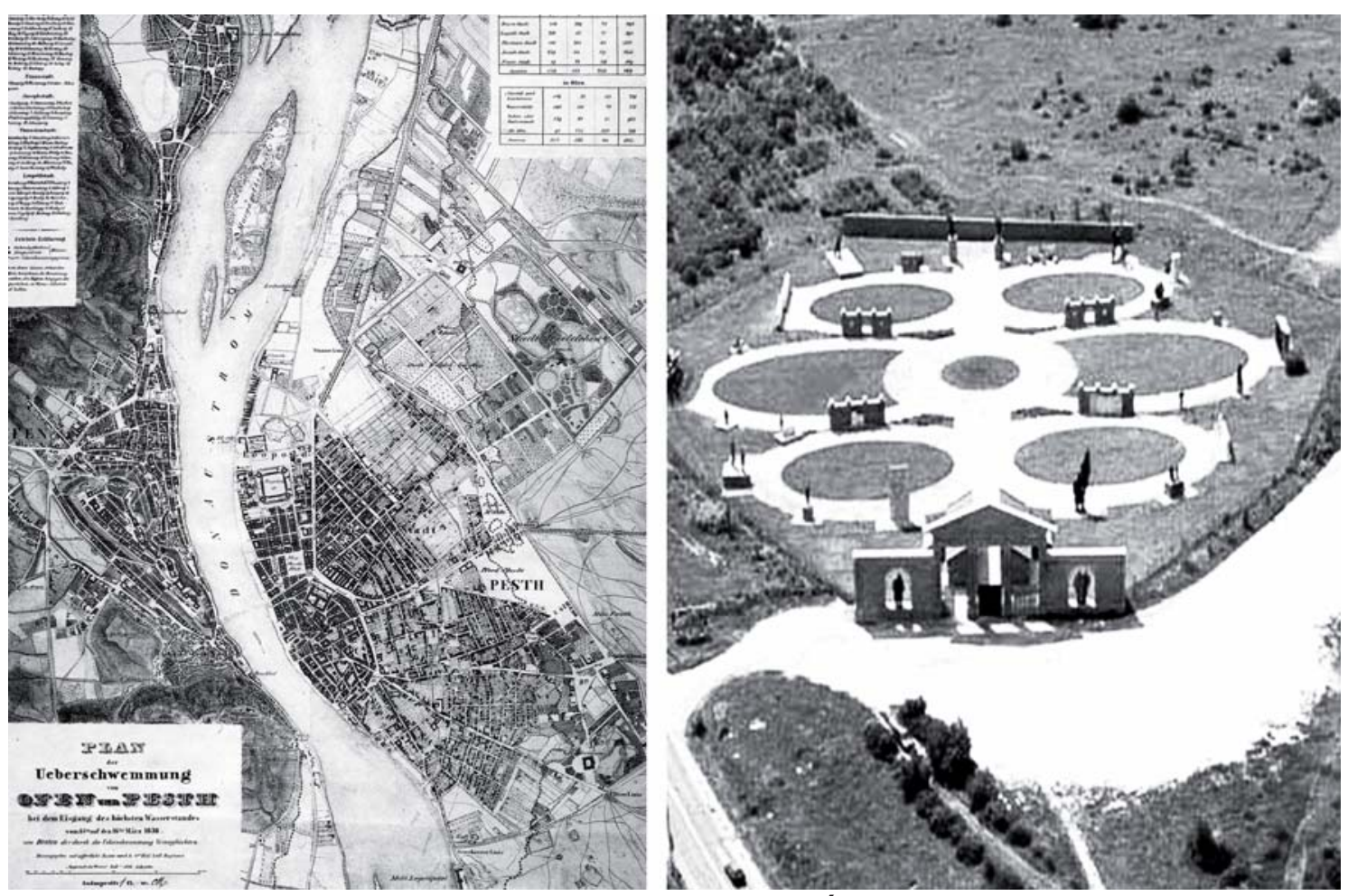

Figura 4. Plano de Pest (1838) y vista aérea de Memento Park. 

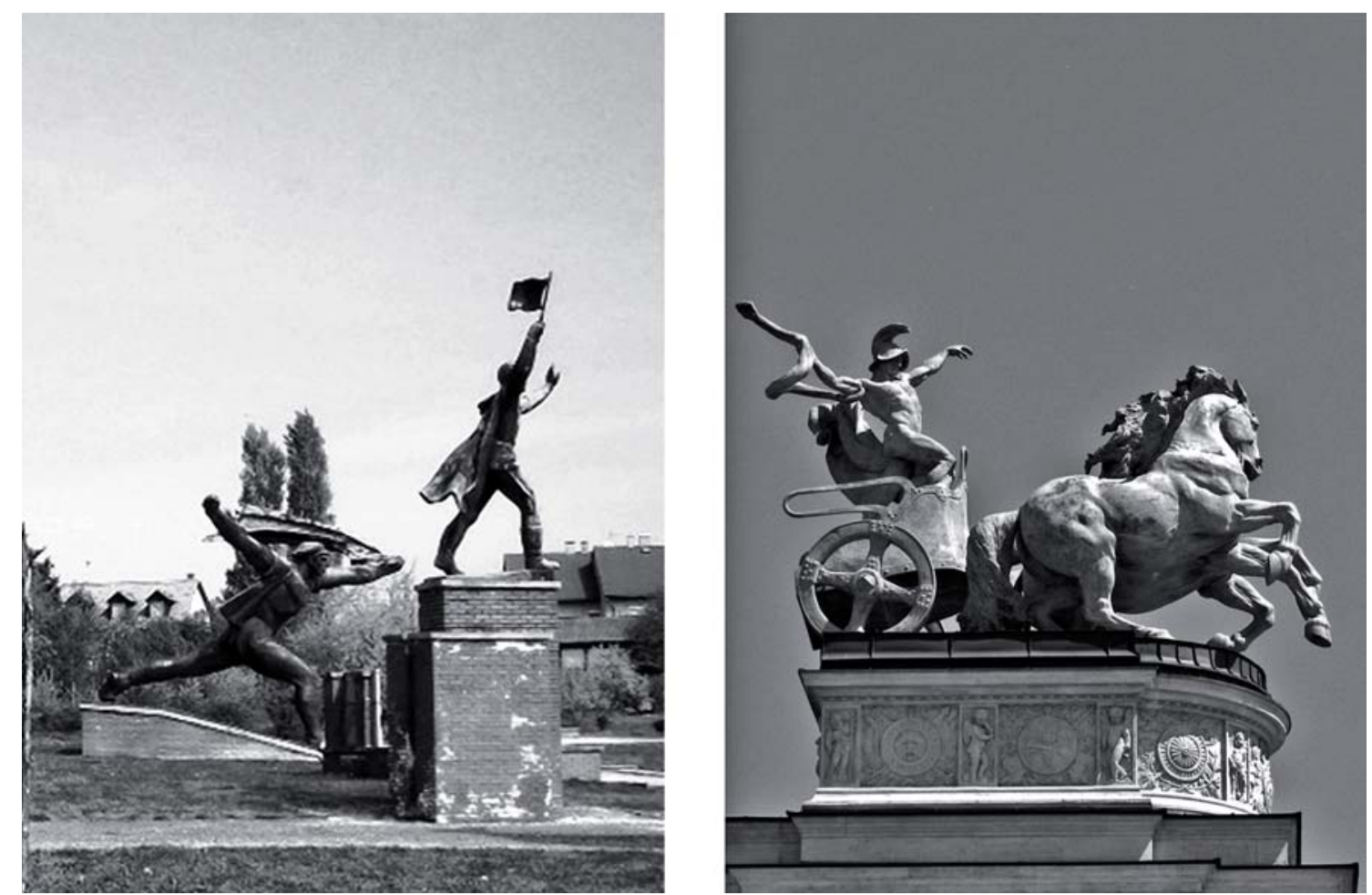

Figura 5. Memento Park; Hösök Tere.

En la cartografía mítica del nacionalismo húngaro tiene mucha relevancia otro grupo de estatuas. Cuando en 1896 se celebró la Exposición del Milenio de Hungría al final de la gran avenida Andrassy de Pest, rematándola, se erigió un conjunto estatuario y monumental conocido como Hösök Tere (Plaza de los Héroes), donde destacan las representaciones de los siete caudillos magiares encabezados por Árpád. Éste fue tapado por una gran tela roja y puesto tras una estatua a Marx -como la que hoy se puede contemplar en el Memento Park- cuando la República Soviética del 19; resultó semiderruido en las guerras mundiales y sobrevivió a diferentes planes de demolición por parte de la República Popular, para ser restaurado desde el historicismo en los noventa y constituirse en uno de los spots turísticos de los tours Praga-Viena-Budapest en la capital de la República de Hungría -además de en punto de encuentro de los neofascistas del partido Jobbik ${ }^{4}$ - (figura 5).

Esa condición de ruina de la ideología del imperialismo austrohúngaro, latente bajo décadas de "socialismo real", que se halla tanto en Hösök Tere como en el Memento Park, es patente en gran parte del extenso casco histórico de Pest -en el interior del segundo anillo del ensanche decimonónico-.

Motivos ideológicos llevaron a las autoridades comunistas a alojar en el simbólico corazón económico y comercial de la ciudad a

\footnotetext{
${ }^{4}$ Tercera fuerza política en el parlamento húngaro.
} 
las clases más desfavorecidas. No obstante, las políticas de vivienda de la República Popular siempre estuvieron orientadas a la construcción de nuevos polígonos de vivienda, quedando el centro de la ciudad en un estado de relativo descuido ${ }^{5}$. Tras la caída del régimen socialista, motivos ideológicos encaminaron a las autoridades húngaras a promover la propiedad privada, favoreciendo la adquisición de viviendas por sus usuarios efectivos. Éstos tuvieron la oportunidad de adquirir en propiedad las mismas por una fracción de su valor de mercado, ya de por sí muy bajo. Ello consolidó en edificios muy degradados a usuarios sin recursos para repararlos. Motivos ideológicos y económicos han impedido por ahora a las autoridades municipales y nacionales emprender las grandes operaciones de embellecimiento estratégico mediante inversión pública que desencadenarían -y han desencadenado- procesos de gentrificación en situaciones análogas en otros contextos históricos. Pese a la evidente rentabilidad turística -e inmobiliaria- que aportarían estos procesos, la contradicción irresoluble de la política de vivienda de Budapest mantiene el statu quo de degradación del parque construido, limitando las operaciones - públicas y privadas- de maquillaje a unos pocos edificios de alto valor simbólico y al entorno de los principales ejes del turismo ${ }^{6}$.

Hoy, los pasajes en París no existen más allá del simulacro. En cambio, en Budapest, éstos se conservan sin que parezca que haya habido otro motivo que la falta de dinero para demolerlos. "Los objetos que explicitan las expectativas de un mundo mejor del colectivo del pasado, plasmadas y conservadas en tales objetos como imágenes oníricas", que exponen cómo "esas expectativas y anhelos se han transmitido al presente: como ruinas, aniquiladas por la perpetuación y reiteración de las mismas relaciones sociales de producción" (Romero Cuevas 2010: 368), son la realidad material cotidiano en el centro de Pest actual.

Este mismo ha sido el material de trabajo del cineasta húngaro Forgács Péter. En su serie Private Hungary, Forgács lleva trabajando desde 1988 con películas caseras realizadas fundamentalmente por miembros de la burguesía de Budapest desde la década de los 20, donde se registra la vida cotidiana de familias en entornos cotidianos apacibles, antes $-\mathrm{y}$ en ocasiones después- de verse truncadas por los dramas históricos del siglo XX.

${ }^{5}$ Con paradójicas excepciones de "gentrificación socialista" (Cook 2009).

${ }^{6}$ El proyecto en marcha de Corvin Promenade, en la parte más degradada de Józsefváros, del que se hablará más adelante, supone tal vez el primer intento a gran escala de gentrificación del centro de Pest. Para profundizar en el asunto de la rehabilitación del casco de Budapest, vid. Simon (2009). 
Jenô was a solid catholic person, a banker, he lived then in his beloved town, Budapest, wich was called the Paris of East Europe. He made films with an $8 \mathrm{~mm}$. camera through the years, as a diary [...]. (Forgács, dir., 1989) ${ }^{7}$

La arqueología del tiempo de Forgács se pregunta "¿por qué no podemos cambiar el presente $\mathrm{y} / \mathrm{o}$ el pasado, nuestras vivencias reales, con la fuerza y el poder de la memoria? ¿iPodemos hacer otra cosa!? ¿Podría ser borrada la obscenidad de la historia -pública y privada- por la revelación de la ucronía?" (Forgács 2011: 322).

Este autor explota fuera del continuo histórico imágenes domésticas, filmadas originariamente para ser exhibidas en el ámbito familiar y privado, y les otorga un nuevo significado. Combinando el trabajo de archivo, de documentación e interpretativo, que lo dota de un valor añadido expresivo mediante el empleo de ralentizaciones, congelados, tintados, coloreados o imágenes en negativo, o mediante la sincronización de música e imagen, hace que su cine "ucrónico cree un mosaico de tiempo alternativo que trata de responder al enigma de los hechos" (Forgács 2011: 322).
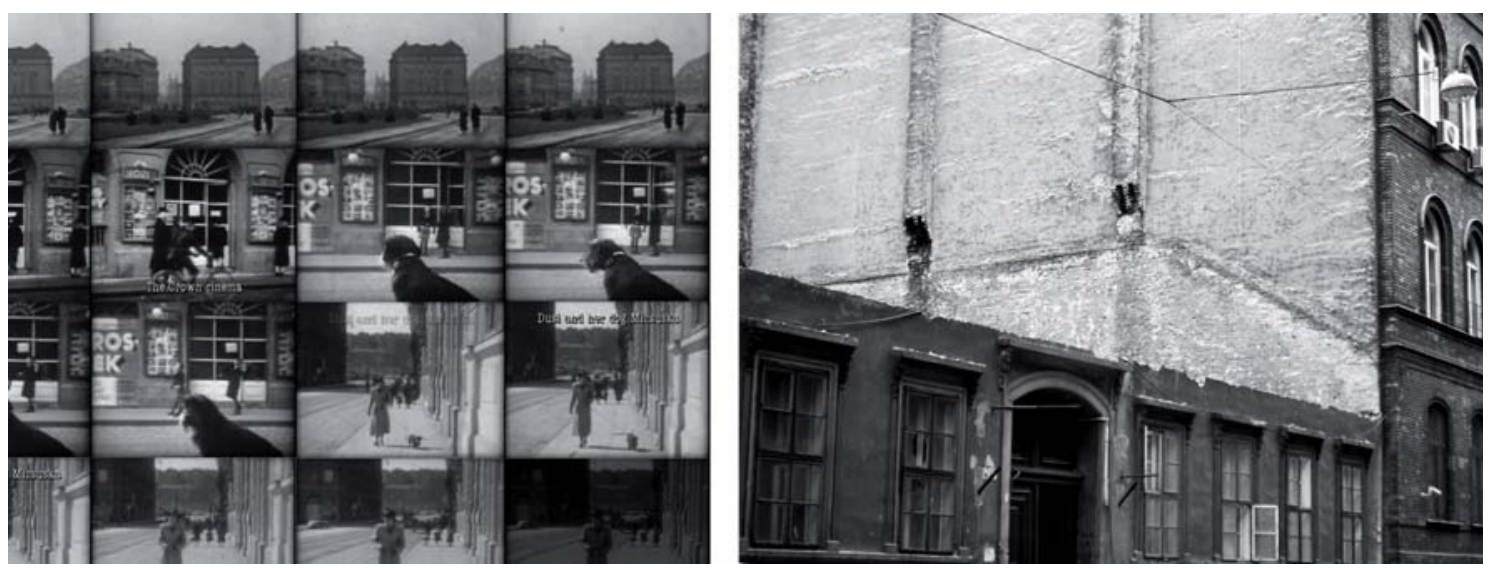

Figura 6. Dusi és Jenő, de Folgács Péter; Pest (2006).

"Los fenómenos urbanos se experimentan al mismo tiempo como algo subjetivo y como algo soñado" (Buck-Morss 1995: 61). Las películas privadas que Forgács rescata -como un trapero del material desechado de las generaciones anteriores- "están constituidas por las imágenes arrancadas al flujo del aquí y el ahora. [...] Lo que ayer -o hace 100 años- era profundo y emocionante, puede resultar cómico o sentimental en la actualidad, [lo que] nos sugiere que la vida puede vivirse de otra forma y no de ésta" (Forgács 2011: 322).

Forgács retoma el trabajo sobre las imágenes del pasado entrelazadas con las del presente en el ruinoso centro de Pest -

${ }^{7}$ Primeras palabras de la voz en off -Forgács Péter- que acompaña las imágenes de Dusi és Jenő. 
simultaneidades de lo no-simultáneo- de otro aquincense: André Kertész. Kertész, nacido Andor, fue uno de los más grandes fotógrafos de su generación y uno de los pioneros del fotoperiodismo ${ }^{8}$. Realizó sus primeros trabajos en el Budapest prebélico de principios del XX y, contemplando sus fotografías, es posible reconocer muchos fenómenos urbanos que se dan hoy cuando no los edificios concretos, que muy a menudo también-.

Kertész, como Benjamin, emigró a París, pero, a diferencia de éste, huyó a América antes de la llegada de los nazis, lo que le permitió disfrutar de una prolongada existencia. Fuera de su país encontró el reconocimiento profesional, especialmente en la capital francesa, donde fue uno de los numerosos emigrantes húngaros que, como Brassaï o Robert Capa, probaban suerte en el periodo de entreguerras. Con algunos de ellos compartió los círculos Dadá en su época de mayor éxito. Sin embargo, en cierto modo nunca abandonó del todo la capital húngara, ya que nunca llegó a ser capaz de comunicarse en inglés o francés.

Ya al final de su vida, Kertész volvería a fotografiar su ciudad natal. En el año 71 realizó una serie de fotografías titulada Budapest, particularmente significativa, sobre la naturaleza de esta ciudad. En ellas aparecen imágenes de niñas o jóvenes junto a estatuas en escenarios urbanos de la ciudad. La yuxtaposición de naturaleza petrificada y naturaleza transitoria que el veterano maestro de la fotografía realiza en esta serie, tiene la potencia de mostrar la particular atmósfera de Budapest, donde el presente convive cotidianamente con los phantasma del pasado reciente (figura 7).

También en el Memento Park encontramos ejemplos de convivencia de las imágenes petrificadas del pasado con la experiencia fugaz del presente. Éste aún encierra otra ruina más, entremezclada con las anteriores: la del capitalismo, que exalta su banalidad en el fenómeno del turismo -y que, después de todo, es la infraestructura económica de este parque-. Los autobuses de turistas que cada día del año son conducidos al Memento Park muestran como "la experiencia se marchita en una serie de souvenirs, [como reflejo del] esquema de transformación de la mercancía en el objeto de coleccionista" (Benjamin 2005: 689).

Si bien en estas nuevas miradas a los "dioses caídos" es perceptible la rotura del aura, desde el valor cultual que en algún momento debieron de tener los héroes del comunismo reificados, la superposición de ruinas en el Memento Park ofrece el claro destello de la verdad sobre el proceso de transmisión cultural como un cortejo

8 "Hagamos lo que hagamos, ya lo ha hecho Kertész antes", dijo Henry CartierBresson. 
triunfal en el que "los dominadores de hoy pasan sobre los que hoy yacen bajo tierra" (Benjamin 2005: 309).
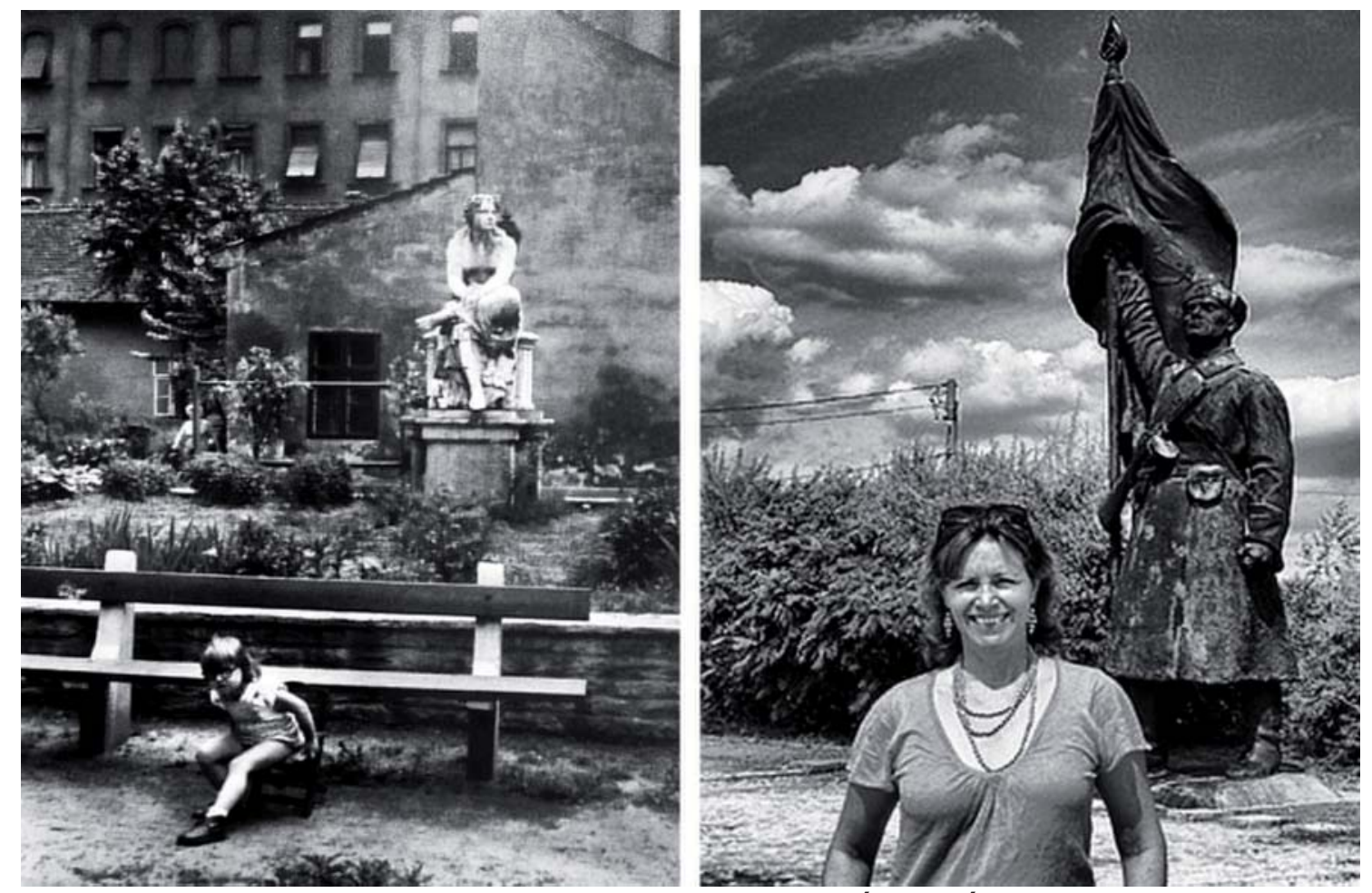

Figura 7. Madre e hija, Budapest 1971, André Kertész; Memento Park.
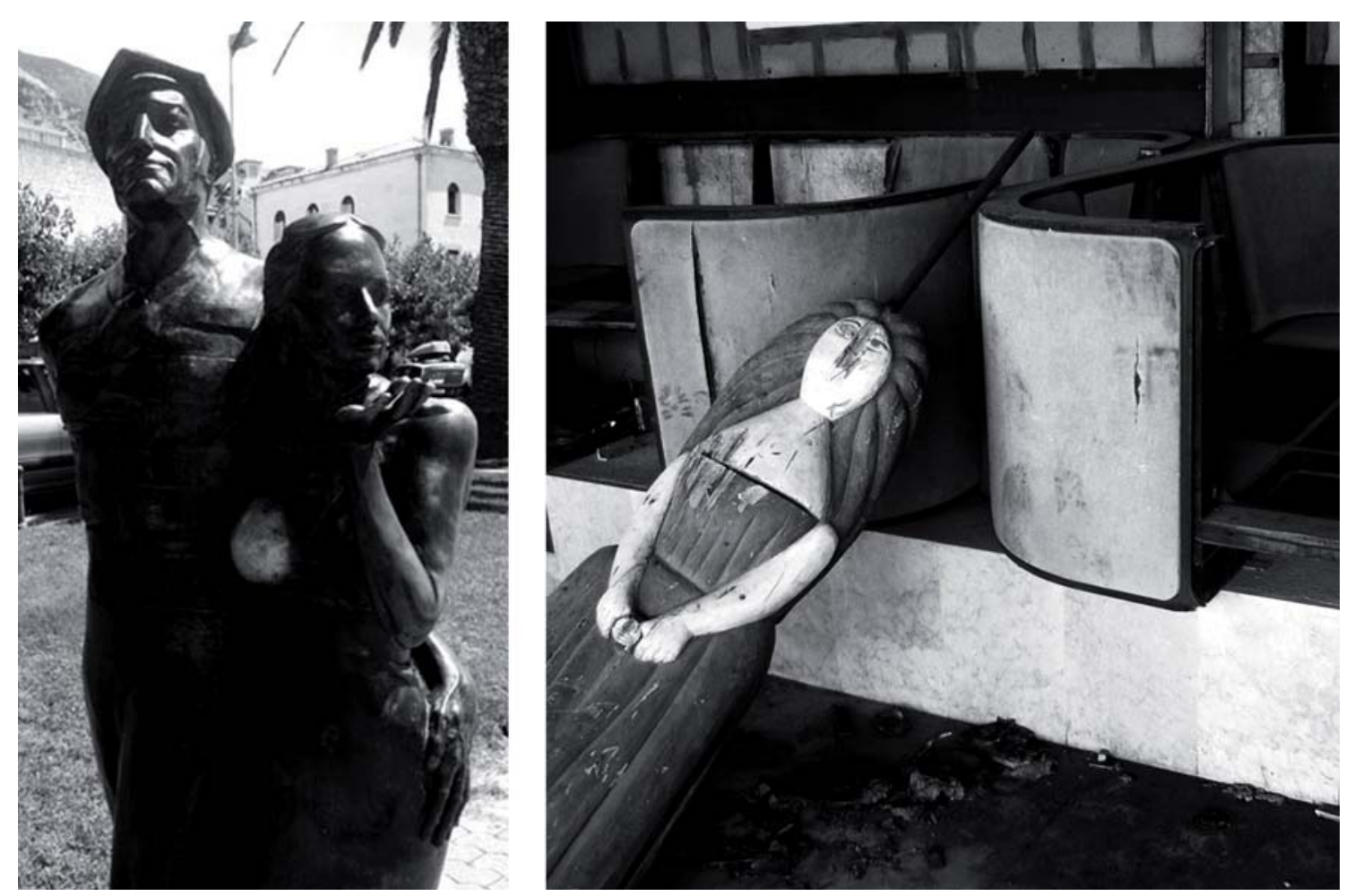

Figura 8. Estatua a la turista en Makarska; Hotel abandonado en Kupari. 
No hay que alejarse mucho para encontrar imágenes que indiquen lo perecedero de la fantasmagoría actual. La pequeña localidad de Makarska descansa donde las verdes laderas de las montañas Biokovo tocan el mar Adriático, cerca de la desembocadura del río Neretva en la costa dálmata. Su pintoresco emplazamiento y su clima soleado han hecho del turismo la principal fuente de ingresos local. Es por ello que, caída la de Tito, el pueblo levantó una estatua al turista en el paseo marítimo. Tal como pasa con la estatua a Julieta de Verona, la broncínea teta de la turista femenina ha sido desgastada por el roce hasta perder su pátina. En su versión desenfadada e inconsciente del pie del santo desgastado por la infinita repetición de besos devotos hasta casi desaparecer, la turista croata ilustra la erosividad del turismo y su asombrosa capacidad para desgastar la realidad (figura 8 ).

La ruina de la ciudad del turismo alcanza su plena dimensión constructiva en el pueblo de Kupari, once kilómetros al sur de Dubrovnik. El resort turístico Kupari, en funcionamiento desde los años 20, que llegó a estar compuesto de los hoteles Pelegrin, Kupari, Goricina I, Goricina II, Grand y Mladost, sumando alrededor de 2000 camas de capacidad, más un camping con capacidad para 4500 visitantes más, resultó profundamente dañado en la guerra de la exYugoslavia, cuando alojó a los diferentes ejércitos en lucha por la antigua Ragusa. A la espera de atrevidos inversores que le devuelvan su brillo (MTRC 2005), testimonia hoy "el declive de una época económica, que el sueño colectivo confunde con el declive del mundo mismo" (Benjamin 2005: 610).

Estos paisajes postbélicos en los Balcanes admiten su lectura como ur-paisajes del futuro, especialmente si es cierto que "las ruinas de una época son más elocuentes en cuanto a su plan general que los oropeles del esplendor" (García García 2010: 165).

El mencionado proyecto de Benjamin de cuestionar la visión moderna de la "historia como progreso en cuanto a tal, no dependiente de la voluntad consciente de los sujetos, de mejora en marcha de todas las dimensiones de lo humano", se debe a que entiende que esta visión "hace un profundo daño a los esfuerzos por confrontar críticamente con el presente y por impulsar una praxis transformadora en profundidad" (Romero Cuevas 2010: 569)9. Para ello, pretende "llevar a cabo una historia enervante de la praxis del colectivo oprimido" (Romero Cuevas 2004: 163) a partir de los objetos que nos rodean.

Para Benjamin, "la explosividad cognoscitiva en sentido político tiene lugar cuando el presente como tiempo-ahora es bombardeado

9 Que es para Benjamin el aliado ideológico del reformismo etapista socialdemócrata (Romero Cuevas 2010: 569). 
con fragmentos empíricos profanos del pasado" (Benjamin 2005: 576). Pues bien, ese bombardeo es constante en esta ciudad. Si la semántica del fragmento benjaminiana es cierta, y si la devaluación de la -nueva- naturaleza y su estatuto como ruina pudieran llegar a ser políticamente instructivas, deberían serlo en Budapest. En ésta se hace posible distinguir entre la tradición de los grupos cultural y socialmente dominantes, poseedores de los medios de transmisión cultural, y la discontinua tradición de los oprimidos, mal disimulada por los grupos hegemónicos debido a las peculiaridades de la historia reciente en la ciudad.

Si hubiera contenida en esas imágenes la fuerza necesaria para "despertar del mundo de nuestros padres" (Benjamin 2005: 1214), debería haber surgido en esta ciudad "una reforma de la conciencia consistente en sacudir al mundo del sueño fuera de sí mismo" (Marx apud Benjamin 2005: 583). "¿Es posible que "las ciudades grises, oscuras o siniestras sean mucho más emocionantes, más libres y más creativas?" (Pérez de Lama 2004).

No se atisba en el futuro próximo, sin embargo, que la didáctica revolucionaria alumbre la alborada del día de la revolución. Más bien al contrario, el capitalismo más implacable se desarrolla con notable éxito en Hungría, apoyado en el viejo báculo del nacionalismo ${ }^{10}$. De hecho, la preocupante situación en la que se encuentra la numerosa minoría gitana húngara tras la escalada neonazi que vive el país ${ }^{11}$, encuentra expresión física en el principal desarrollo urbano en marcha en la ciudad. Corvin Promenade se trata de un ambicioso proyecto de gentrificación del centro de Pest que, de la mano de una nueva línea de metro, se propone la monumentalización, a la vez comercial y política, de 22 hectáreas del distrito de Józsefváros, el barrio donde se concentra la población cíngara en la ciudad (Cook 2009). Tras el habitual discurso sobre regeneración urbana del entorno degradado, de nuevo, los grupos hegemónicos inducen la exclusión al no-ser de aquello que pueda desmentir la totalidad verdadera que la construcción mitológica al servicio de los opresores reclama. "El control de lo urbano, lo que se agita sin cansarse -ese puro trabajo[...] que todo orden institucionalizado intenta" (Delgado 2007: 101).

${ }^{10}$ Que más del $60 \%$ de los húngaros $-y$ un muy significativo $70 \%$ de los jóvenesafirmen preferir las condiciones de vida que se daban durante régimen socialista que las que sufren bajo el capitalismo (Kutatópont KFT 2012), ilustra tanto sobre la experiencia urbana de Budapest como sortilegio ante el mito del progreso histórico, como sobre la representatividad "democrática" del régimen político actual en occidente.

${ }^{11}$ Los sucesos en el pueblo de Gyöngyöspata en Semana Santa de 2011, con cientos de gitanos huyendo de las milicias neofascistas que controlaban el pueblo, de los que la prensa internacional se hizo eco, difundieron en el extranjero el empeoramiento de la situación a la que el colectivo romaní se enfrenta en Hungría tras el ascenso electoral de las opciones de extrema derecha. 
La esperanza de Benjamin en el potencial de la redención de los oprimidos del pasado en la praxis, desencadenada por una "hermenéutica de la discontinuidad" (Romero Cuevas 2004: 171), queda en entredicho. Más bien, se hace patente la "genuina pesadilla de la historia que vemos fugazmente cuando quiera que empezamos a sentir lo permanente de sus fallos y lo irredimible de generación tras generación de muertos. (Jameson 2011).

No obstante, en el plantar cara a la negatividad acabada muestra cada individuo algo de la dignidad inconmensurable de toda la humanidad (Schweppenhäuser 2010: 57). Existe otro Budapest que "no se percibe como antigua ni moderna, sino una cultura improvisadora, liberada e incluso nutrida por la rápida decadencia de la ciudad" (Buck-Morss 1995: 46). Existe una joven sociedad húngara, dedicada al "asalto jubiloso de las ruinas de la civilización burguesa" (Rendueles y Useros 2010: 19), que encuentra en la escena romkocsma -literalmente, garito en ruinas- su punto de encuentro.

El fenómeno del romkocsma surgió hace algo más de diez años en el distrito de Erzsévetváros. Este barrio, el antiguo gueto judío dentro del centro de Pest, presenta(ba) un acusado estado de abandono. Fue en este contexto donde las primeras asociaciones culturales, o incluso promotores privados, comenzaron a lograr cesiones o a alquilar a bajo coste edificios en estado de abandono, para su uso como lugares de producción y difusión de arte contemporáneo, desde la danza al circo o el teatro, pasando por salas de conciertos, estudios de grabación y ensayo, talleres y exposiciones, áreas multimedia, cibercafés, fanzinotecas, etc. Todo ello es desarrollado al hilo de proyectos generados por los propios centros, los jóvenes que los frecuentan, o los artistas o asociaciones que lo soliciten. Estas Zonas Temporalmente Autónomas ${ }^{12}$ dan vida a la creación y a su difusión y se transforman en lugares para la convivencia -performances, conciertos, cafés, restaurantes...-.

12 "Forma de sublevación que no atenta directamente contra el estado, una operación guerrillera que libera un área -de tierra, de tiempo, de imaginación- y entonces se autodisuelve para reconstituirse en cualquier otro lugar o tiempo, antes de que el estado pueda aplastarla" (Bey 1990: 3). 

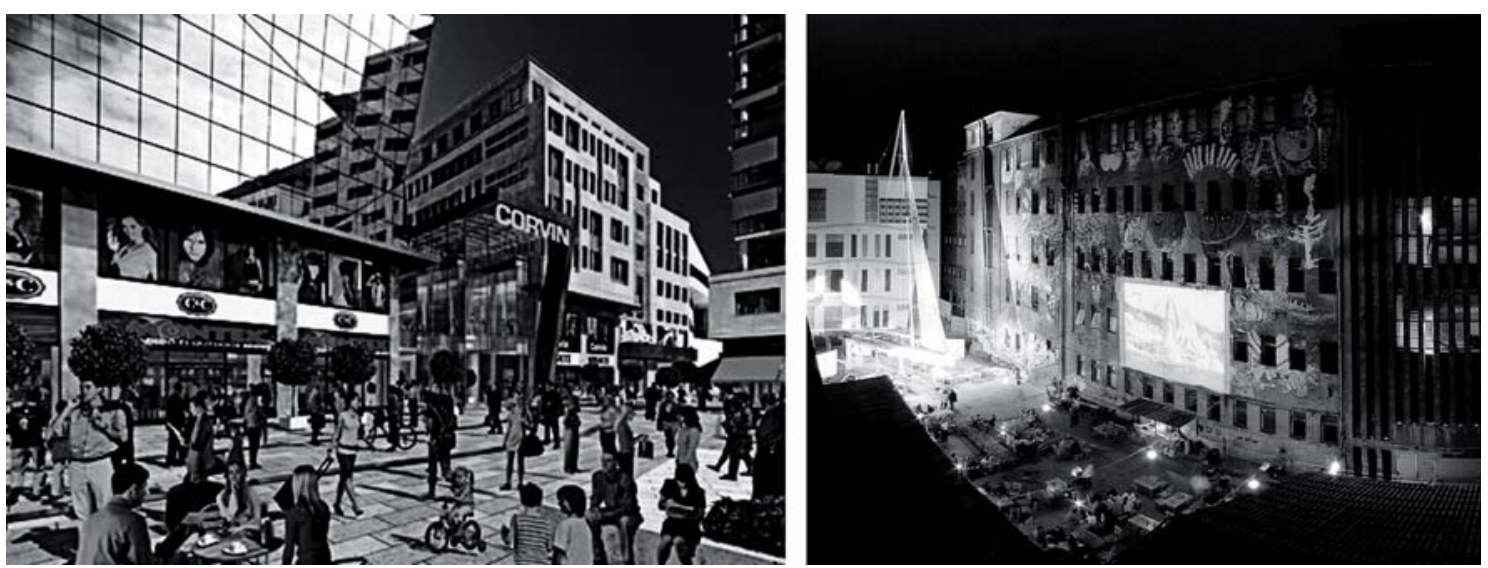

Figura 9. Infografía de Corvin Promenade; Romkocsma Tûzraktér.

Los edificios, rápidamente ocupados, en poco tiempo son precariamente acondicionados con mobiliario reutilizado, lo que contribuye a generar una atmósfera artificial y lúdica, hecha de objetos encontrados en el ciclo de producción y consumo, que cierta cultura contemporánea asocia con los espacios de producción artística. Durante un tiempo -unos meses o unos años, tal vez tan solo unas semanas- desarrollan su actividad $y$, fruto de las condiciones del edificio o de las intenciones de la propiedad, se ven obligados a interrumpirla para reaparecer poco tiempo después en otro emplazamiento: lo que antes era una vieja fábrica puede hoy ser un antiguo colegio, un estropeado garaje puede ser una manzana entera de viviendas en pocos meses, etc.

Por supuesto, esta escena tiene mucho en común con otros fenómenos urbanos contemporáneos similares -especialmente con el de las projekt häuser berlinesas-. Sin embargo, se dan algunas notables diferencias. Por un lado, la presión inmobiliaria a la que estas situaciones análogas se enfrentan, por ejemplo en Berlín, es muy superior que en Budapest, lo que ha contribuido a su desgaste en el tiempo. Resultan de ello paradigmáticos la venta del edificio del famoso squat Tachelles -el último del Mitte- por parte de sus inquilinos a una inmobiliaria (Gómez 2011), o la situación análoga en la que se encuentra el barrio okupado de Christiania con el estado danés (Pawlicki 2011). Por otra parte, la ubicación algo periférica de los principales circuitos turísticos -pocos turistas pasan más allá del fin de semana en la ciudad- ha frenado la parquetematización del romkocsma.

Es además una escena autoconsciente, como se evidencia por la abundante actividad en torno al asunto en internet o las recientes jornadas que el Kortárs Épitészeti Központ (centro húngaro de arquitectura contemporánea) le ha dedicado recientemente. Con motivo del cierre -temporal- de uno de los romkocsma pioneros, el 
Tûzrakter, en marzo de 2009, un carnaval-manifestación permitió al movimiento exhibirse por las calles del centro de Budapest ${ }^{13}$.

Cabría preguntarse si las particulares disposiciones de imágenes dispuestas ante el observador que alza la mirada en Budapest han supuesto la espita que ha encendido fenómenos como el romkocsma. Lo que interesa, sin embargo, no es sino la existencia misma del fenómeno y, además, tal vez sólo sea una coincidencia. No obstante,

cabe una lectura de las ideas de Walter Benjamin convincente para esta situación: una lectura que conciba los actos políticos concretos, y en cada caso limitados, de oposición, reivindicación, construcción y resistencia de los de abajo como pudiendo encontrar una base motivacional en su vinculación reflexiva con los de la tradición discontinua, y marcada por la derrota, de las luchas por la emancipación realizadas en el pasado. (Romero Cuevas 2010: 371)

La posibilidad de trazar esta tradición discontinua de los oprimidos pasados y presentes encuentra en esta ciudad un contexto idóneo. Sin embargo, el paisaje en ruinas que se halla condensado en el Memento Park muestra que, si éste es un proyecto posible, ha de serlo libre de "cualquier atisbo de triunfalismo" (Arribas 2010: 78), por toda la acumulación de escombros de la historia, y porque, frente a la tradición cultural dominante "hecha de clisés y puntos fijos en torno a los monumentos y monumentalizaciones, lo que hay en realidad es otra cosa: [...] el universo de los lugares sin nombre: una ectoponimia ${ }^{14}$. [...] Memorias potentes sin poder, que se enfrentan a un poder impotente $\mathrm{y}$ a sus ciudades espectaculares, triunfales, falsas" (Delgado 2007: 103).

¿Tiene algún sentido entonces el proyecto de elaboración de una mitología al servicio de los oprimidos? El valor de tal proyecto no sólo radicaría en qué se recuerda y a quién se recuerda, sino en "qué implicaciones tiene el acto de recordar para el comportamiento actual de los sujetos en su realidad vital" (Romero Cuevas 2010: 370) ${ }^{15}$. La construcción de una "memoria moral que se convierta en fuerza motivacional para un comportamiento activo intolerante con las injusticias en todas sus formas" (Romero Cuevas 2010: 370) no

13 Tal vez síntoma su mismo final. "Tan pronto como una TAZ es nombrada representada y mediatizada- debe desaparecer, desaparece de hecho, dejando tras de sí un vacío. Resurgiendo de nuevo en otro lugar, e invisible de nuevo en tanto que indefinible en los términos del Espectáculo" (Bey 1990: 3).

${ }^{14}$ Ectoponimia es el espacio vacío de los lugares sin nombre y los nombres sin lugar, frente a la toponimia, nombre de lugar, lugar con nombre (Delgado 2007: 102).

15 Hay ejemplos presentes de utilización de la memoria de las víctimas (del nacionalsocialismo, por ejemplo, pero no sólo) como justificación ideológica para la perpetración de comportamientos injustos y criminales. 
ofrecería reparación al irreparable sufrimiento de los asesinados, pero tal vez pueda ser una herramienta para cambiar el presente con la fuerza y el poder de la memoria. ¿iPodemos hacer otra cosa!?

\section{Bibliografía}

ARRIBAS, Sonia (2010): "El mundo en miniatura en Goethe y Benjamin: Promesa de felicidad y ruina en 'La nueva Melusina'". Constelaciones, vol. 2, pp. 61-78.

BENJAMIN, Walter (1990): El origen del drama barroco alemán. Madrid: Taurus.

BENJAMIN, Walter (2005): Libro de los Pasajes. Madrid: Akal.

BEY, Hakim (1990): "La Zona Temporalmente Autónoma" [en línea], en ccapitalia.net. En: www.ccapitalia.net/tip/process/hyo/bey taz.pdf [Consulta: 27/02/2012].

BUCK-MORSS, Susan (1995): Dialéctica de la mirada. Madrid: Visor.

COOK, Ian (2009): "Are you ready to move?" [en línea], en Museo de los desplazados. http://www.lefthandrotation.com/museodesplazados/ficha cook.htm [Consulta: 27/02/2012].

DELGADO, Manuel (2007): "La desactivación de lo urbano", en David L. Lagunas (ed.), Antropología y turismo, pp. 91-108. México DF: UAEH / Plaza \& Valdés.

FORGÁCS, Peter (2011): "Arqueología del tiempo o memorias alternativas", en VV AA, Documentamadrid 2011, pp. 320-322. Madrid: Documentamadrid.

GARCÍA GARCÍA, Luis Ignacio (2010): "Alegoría y montaje. El trabajo del fragmento en Walter Benjamin". Constelaciones, vol. 2, pp. 158-185.

GERMUSKA, Pal (2008): Between theory and practice: planning socialist cities in Hungary. Urban Machinery. Cambridge (Mass.): MIT Press.

GÓMEZ, Juan (2011): "Un millón de euros para los 'okupas' del Tacheles" [en línea], en El País Cultura, 07/04/2011. En: http://cultura.elpais.com/cultura/2011/04/07/actualidad/1302127206 850215.html [Consulta: 27/02/2012].

HEGEDÛS, Sandor (2008): "Védnökseg a martírsírok fellet: Kalamár Jozsef" [en línea], en $A$ szabadszág. En: http://www.aszabadsag.hu/cikkek/2008/19/mozgalom.html [Consulta: 27/02/2012].

HOZZÁFÉRÉS (2011): Helységnévkönyv adattár 2011 [en línea], en KSH. En:

http://portal.ksh.hu/pls/ksh/docs/hun/hnk/Helysegnevkonyv adattar 2011.xls [Consulta: 27/02/2012].

JAMESON, Fredric (2011): "Lecturas de Benjamin" [en línea]. Revista Minerva. En: http://www.revistaminerva.com/articulo.php?id=474. [Consulta: 27/02/2012].

KUTATÓPONT KFT (2012): "Magyar Ifyúság 2012" [en línea]. Kutatópont KFT.

http://kutatopont.hu/files/2012/02/magyar ifjusag 2012.pdf

[Consulta: 27/02/2012]. 
MH (2012): "Magyarország Helységnévtara 2012" [en línea]. Központi Statisztikai Hivatal.

En: http://www.ksh.hu/apps/!cp.hnt2.telep?nn=13578 [Consulta: 27/02/2012].

MTRC (Ministry of Tourism of the Republic of Croatia) (2005): "Tourist Complex Kupari" [en línea]. Ministry of Tourism of the Republic of Croatia. En: $\quad$ http://www.mint.hr/UserDocsImages/Kupari.pdf [Consulta: 27/02/2012].

OTTHOM CENTRUM (2006): "Panelpiac - túl a mélyponton?" [en línea]. Otthom Centrum. En: http://www.oc.hu/ingatlanpiac/269 [Consulta: 27/02/2012].

PAWLICKI, Jacek (2011): "El final de la generación de las flores" [en línea]. Europa Press.

En: http://www.presseurop.eu/es/content/article/533001-el-final-de-lageneracion-de-las-flores [Consulta: 27/02/2012].

PÉREZ DE LAMA, Javier (2004): "Nuevas perspectivas para la intervención en los centros históricos. La ciudad de la multitud" [en línea]. Hackitectura.

En: http://hackitectura.net/osfavelados/txts/centros historicos/version w eb/texto 01 web.html [Consulta: 27/02/2012].

RENDUELES, César; y USEROS, Ana (2010): Atlas Walter Benjamin Constelaciones. Madrid: CBA.

ROMERO CUEVAS, José Manuel (2004): "La idea de una hermenéutica de lo concreto en Benjamin y Adorno: ¿más allá de Gadamer?". Thémata, vol. 34, pp. 159-171.

ROMERO CUEVAS, José Manuel (2010): "Sobre la actualidad de Walter Benjamin". Constelaciones, vol. 2, pp. 367-371.

SCHWEPPENHÄUSER, Hermann (2010): "Para una fisionomía de un fisionomista". Constelaciones, vol. 2, pp. 14-37.

SIMON, Mariann (2009): "La cara oculta: rehabilitaciones recientes en Budapest". Arquitectura COAM, núm. 355, pp. 90-97.

UK (2010): Studio Metropolitana. Urbanisztikai Kutatóközpont [en línea]. En: http://www.studiometropolitana.hu/munkainkbol.html [Consulta: 27/02/2012].

\section{Filmografía}

SZEMES, Mihály; y MARKOS, Miklós (dirs.) (1959): Kölyök. (Chiquilla) Hungría: Hunnia.

FORGÁCS, Péter (dir.) (1989): Dusi és Jenő. Hungría. 